MRS. MARIA ELENA SOLÀ-MIRAVETE (Orcid ID : 0000-0003-0434-6044)

Article type : Original Article

\title{
Nursing assessment as an effective tool for the identification of delirium risk in older in-patients: a case-control study
}

Running head: Nursing assessment for delirium risk in inpatients

Elena SOLÀ-MIRAVETE MSc RN ${ }^{1}$, Carlos LÓPEZ $\mathrm{PhD}^{2^{*}}$, Estrella MARTÍNEZ-SEGURA MsC RN ${ }^{3}$, Mireia ADELL-LLEIXÀ MSc RN ${ }^{4}$, Maria Eulàlia JUVÉ-UDINA PhD ${ }^{5}$, Mar LLEIXÀ-FORTUÑO PhD

${ }^{1}$ Department of quality, Hospital de Tortosa Verge de la Cinta, Universitat Rovira Virgili, Terres de l'Ebre Campus, School of Nursing, Tortosa, Spain.

${ }^{2}$ Molecular Biology and Research Section, Hospital de Tortosa Verge de la Cinta, IISPV, Universitat Rovira Virgili, Tortosa, Spain.

${ }^{3}$ Emergency Services, Hospital de Tortosa Verge de la Cinta, Universitat Rovira Virgili, Terres de l'Ebre Campus, School of Nursing, Tortosa, Spain.

${ }^{4}$ Dialysis Service, Hospital de la Santa Creu, Jesús, Universitat Rovira Virgili, Terres de l'Ebre Campus, School of Nursing, Tortosa, Spain.

${ }^{5}$ Bellvitge Biomedical Research Institute (IDIBELL), Bellvitge University Hospital, Health Universitat de Barcelona Campus, School of Nursing, Barcelona, Spain.

${ }^{6}$ Nursing department, Universitat Rovira Virgili, Terres de l'Ebre Campus, School of Nursing, Tortosa, Spain.

*Address for proof and corresponding author: Carlos López, Molecular Biology and Research Section, Hospital de Tortosa Verge de la Cinta, C/ Esplanetes no 14, 43500-Tortosa, Spain. Phone: 34-977-519-104. Fax: 34-977-519-104. E-mail: clopezp.ebre.ics@gencat.cat

\section{Acknowledgments}

We thank Glòria Puntes, Montserrat Martí, Pilar Escoda, Bibiana Fontanet, Isabel Fort and Jacquelin Maresma, for its invaluable assistance in data collection, and Neus Jové for their excellent secretarial work.

This article has been accepted for publication and undergone full peer review but has not been through the copyediting, typesetting, pagination and proofreading process, which may lead to differences between this version and the Version of Record. Please cite this article as doi: $10.1111 /$ jocn. 13921

This article is protected by copyright. All rights reserved. 
Funding Research grant from Dr. Ferran Foundation

Competing of interest The authors declare that they have no competing interests

\section{Abstract}

Aims. To evaluate the usefulness of comprehensive nursing assessment as a strategy for determining the risk of delirium in older in-patients from a model of care needs based on variables easily measured by nurses.

Background. There are many scales of assessment and prediction of risk of delirium, but they are little known and infrequently used by professionals. Recognition of delirium by doctors and nurses continues to be limited.

Design and methods. A case-control study. A specific form of data collection was designed to include the risk factors for delirium commonly identified in the literature and the care needs evaluated from the comprehensive nursing assessment based on the Virginia Henderson model of care needs. We studied 454 in-patient units in a basic general hospital. Data were collected from a review of the records of patients' electronic clinical history.

Results. The areas of care that were significant in patients with delirium were dyspnoea, problems with nutrition, elimination, mobility, rest and sleep, self-care, physical safety, communication and relationships. The specific risk factors identified as independent predictors were: age, urinary incontinence, urinary catheter, alcohol abuse, previous history of dementia, being able to get out of bed/not being at rest, habitual insomnia and history of social risk.

Conclusions. Comprehensive nursing assessment is a valid and consistent strategy with a multifactorial model of delirium, which enables the personalised risk assessment necessary to define a plan of care with specific interventions for each patient to be made. 
Relevance to clinical practice. The identification of the risk of delirium is particularly important in the context of prevention. In a model of care based on needs, nursing assessment is a useful component in the risk assessment of delirium and one that is necessary for developing an individualised care regime.

Keywords: delirium, nursing assessment, risk factors, older inpatients, prediction.

\section{What does this paper contribute to the wider global community?}

- As comprehensive nursing assessment is used in daily clinical practice, it may be an effective strategy for determining suitable interventions for patients at risk in hospitals. The results indicate that nursing assessment is useful as a multicomponent tool in individualised risk assessment of delirium in hospitalised older people.

- A multivariate model that correctly classifies $93.3 \%$ of patients with or without delirium using a comprehensive nursing assessment. 24 out of $30(80 \%)$ risk factors for delirium studied in the nursing assessment form were associated with delirium.

- This individualised assessment could be useful for identifying the risks at the time the patient is admitted and may help the care team focus on the most vulnerable individuals, and plan a good strategy of care aimed at preventing and managing their delirium.

\section{Introduction}

Delirium is a common syndrome that may be presented by older patients admitted to inpatient units (de Castro et al., 2014; Newman, O'Dwyer, \& Rosenthal, 2015). It is considered a frequent and serious complication that can appear after admission. Its appearance is associated with high morbidity, reduced functional status and increased mortality, with major complications in the short and long term (S. K. Inouye, Westendorp, \& Saczynski, 2014; McCleary \& Cumming, 2015; Whittamore et al., 2014). 
Recent studies show an incidence of delirium of $11 \%$ to $42 \%$ in medical patients, and of $10 \%$ to $70 \%$ in surgical patients after surgery (de Castro et al., 2014; S. K. Inouye et al., 2014; Martins \& Fernandes, 2012).

In older people, the multifactorial model of delirium is the most widely accepted and well developed (S. K. Inouye et al., 2014; Newman et al., 2015). The main risk factors identified by validated predictive models in clinical populations of patients can be grouped into predisposing factors (e.g., dementia, cognitive impairment, functional impairment, comorbidity and older age) and precipitating factors (e.g., polypharmacy, infection, iatrogenic events, surgery and dehydration) (S. K. Inouye et al., 2014; Perello Campaner, 2010). Delirium is the result of a complex interaction between the patient's predisposition (vulnerability) and the number and intensity of precipitating (triggering) factors (Grover \& Kate, 2012; S. K. Inouye et al., 2014; Rudolph et al., 2011).

Multifactorial and multicomponent interventions have been described as being the cornerstone of prevention and treatment of delirium (Hshieh et al., 2015; S. K. Inouye et al., 2014). Interventions that try to improve modifiable variables have proved to be effective in preventing the onset of delirium (Strijbos, Steunenberg, van der Mast, Inouye, \& Schuurmans, 2013; Yue et al., 2014). These multicomponent programs highlight the importance of nursing care in preventing delirium (Avendano-Cespedes et al., 2016). In this sense, studies proposing risk assessment scales based on predictive models for identifying those at high risk of developing delirium are particularly relevant to patients who would benefit from multicomponent interventions. These scales have gone beyond simply identifying risk factors, instead using established risk factors to quantify patients' risk of developing delirium during hospitalization.

Several scales have been proposed, but the risk factors most commonly included in them are age, cognitive impairment, impairment in activities of daily living and the severity of the illness. Some of these scales are examined in several reviews, which conclude that their reliability and validity needs to be better established before they can be applied (Adamis, Sharma, Whelan, \& Macdonald, 2010; Newman et al., 2015; Rudolph et al., 2011). There is 
a growing interest in the design of risk assessment scales, and the risk factors have been well established in various studies. Nevertheless, these scales are little known and infrequently used by professionals (Cole, Ciampi, Belzile, \& Dubuc-Sarrasin, 2013; de Castro et al., 2014; Martins \& Fernandes, 2012). Consequently, recognition of both the risk and the early detection of delirium by doctors and nurses continues to be limited (Hasemann et al., 2016). Consequently, the problem is usually addressed from a standpoint that is complex, deficient and delayed (Day, Higgins, \& Koch, 2009; Hsieh, Madahar, Hope, Zapata, \& Gong, 2015).

In hospitals where none of the strategies described has been implemented, it would be necessary to choose an instrument for feasible risk assessment that is also consistent with the multifactorial approach to the prevention and management of delirium (Day et al., 2009; Hasemann et al., 2016; Vidan et al., 2009). The instrument proposed in this study is a comprehensive nursing assessment, performed by the nurse during the admission of the patient when care needs are identified.

This study analyses the items collected in such an assessment in order to identify possible predictors of delirium. Unlike other tools, it is an instrument that is heavily integrated and widely recognised in nursing practice, and as such its acceptance and implementation in the assessment of the risk of delirium would be straightforward.

The comprehensive nursing assessment is the first part of the nursing care process. It can be defined as a planned, systematic, continuous and deliberate process of collection, classification and categorisation of individualised information, for the purpose of recognising individuals' responses to their health, problems and real or potential needs (Kozier, Erb, Blais, \& \& Wilkinson, 2005). It enables the individualised assessment required to define a plan of care involving specific interventions (Suhonen, Valimaki, \& Leino-Kilpi, 2008). The individualisation of interventions in patients at risk is considered to be a very important aspect of care for the prevention of delirium (Henao-Castano \& Amaya-Rey, 2014; O'Mahony, Murthy, Akunne, \& Young, 2011; Suhonen, Gustafsson, Katajisto, Valimaki, \& Leino-Kilpi, 2010).

This article is protected by copyright. All rights reserved. 
If the detection of risk factors in the comprehensive nursing assessment could be demonstrated to be a useful tool for delirium prediction, it would allow us to rationalise our efforts and resources in delirium prevention, given that such an assessment allows practitioners to focus on the needs of the patient at risk.

The main objective of this study was to evaluate the usefulness of the comprehensive nursing assessment as a strategy for determining the risk of delirium among older people admitted to hospital. The secondary objective was to identify predictors of delirium from a model of care needs based on characteristics that may easily be measured by nurses.

\section{Materials and methods}

\section{Study design}

A case-control study was carried out of patients aged 65 years and over, admitted in 20132014 to any of the five conventional in-patient units treating patients in various surgical and medical specialist fields (general surgery, urology, traumatology and orthopaedic surgery, internal medicine, neurology and other medical specialities) at southern Catalonia's leading hospital for acute patient care (Verge de la Cinta Hospital, Tortosa, Spain. Patients admitted to paediatric, obstetric and critical care units were not included in the study as they were not conventional hospital admissions.

The case study was of patients who developed delirium during their hospitalisation (incident delirium). New cases of delirium were reported to the research team, who included the patients in the study on the basis of the score on the Confusion Assessment Method (CAM) (S. Inouye et al., 1990) diagnostic scale, using a scale (CAM-S) adapted and validated for our context by (Gonzalez et al., 2004). Suspicion and identification of delirium by the nurse caring for the patient is communicated to the team of nurses trained in the use of the scale, who confirm or reject the identification in each case. Patients with delirium on admission to the unit (according to CAM-S criteria) were excluded.

This article is protected by copyright. All rights reserved. 
Patients without delirium were assessed daily with the CAM-S and by the team of trained nurses until discharge. Patients who did not meet the criteria for delirium during the hospitalization according to this scale were selected as controls, and matched by sex, medical speciality and in-patient unit. The inclusion criteria for this group were age (65 years old or over), a minimum three-day stay and no episode of delirium during hospitalization. Once the cases and controls had been selected, the variables for study in the nursing assessment were obtained from the clinical records.

The sample size was calculated using GRANMO v.7.12 software, applying a case-control ratio of $1: 2$, an $\alpha$ risk of 0.05 , a $\beta$ risk of 0.2 , assuming the use of two-tailed tests and a 0.5 exposure rate in the control group, with estimated follow-up losses of $0 \%$, to identify a minimum odds ratio of 1.8 to indicate delirium. Calculations were based on 150 cases (people with delirium) and 300 controls (people without delirium).

\section{Variables and data collection}

The specific data collection instrument was designed to include all the variables of interest: risk factors and the care needs of people with delirium. To this end, a working group of six expert nurses (with clinical experience or expertise in nursing care and standardisation of care) was set up. The tasks of this group were to review the potential predictive variables for delirium selected from a literature review: the predisposing risk and precipitating factors according to the literature on predictive models (Ahmed, Leurent, \& Sampson, 2014; S. K. Inouye et al., 2014; Martinez et al., 2012; Newman et al., 2015; Perello Campaner, 2010), the risk factors listed in the NICE guide (NICE, 2010; O'Mahony et al., 2011) and the protocols including the Hospital Elder Life Program (HELP) multicomponent programme (Strijbos et al., 2013; Yue et al., 2014). All the available information was distributed separately among three pairs of expert nurses, and finally compared and agreed among the six experts. The purpose of this review was to interpret and classify all this information according to the specific nomenclature of nursing care, seeking to adapt the selected variables to study the needs assessment model applied by nurses during patient admission. The nursing assessment form used in the study was based on the Virginia Henderson 14- 
needs model (Henderson, 1994), which is the care model used in our centre. The risk factors and other information reviewed by the panel of six expert nurses (NICE guidelines, HELP protocols) were related to 11 of the 14 care needs. Table 1 displays the results of the consensus of the nurse panel, showing the relationship between the care needs of the model and the NICE guideline on delirium, the HELP protocols and the risk factors described in the literature.

The following 11 nursing assessment variables were studied: 1) Breathing: breathlessness (dyspnoea or saturation $<90 \%$ ), respiratory superinfection and oxygen therapy (oxygen with nasal cannula, mask and/or oxygen at home); 2) nutrition: treatment with serum therapy (continuous intravenous fluid therapy), signs of dehydration (elevated blood urea nitrogen, BUN) or dryness of skin and mucous (mouth and nose), restrictive diet (not complete); 3) elimination: urinary incontinence, faecal incontinence, urinary retention, dysuria infection, use of urinary catheter, constipation or diarrhoea; 4) mobility: rest in bed (unable to get up); 5) rest and sleep: habitual insomnia; 6) self-care assistance: medium or high level of dependence for activities of daily living (ADLs) (personal hygiene and grooming, selffeeding, dressing and undressing, getting onto or off the toilet, and ambulation) and total inability for self-care; 7) temperature: fever on admission ( $\left.\geq 37.5^{\circ} \mathrm{C}\right)$; 8 ) hygiene and integument: ulcer risk due to moderate or high pressure according to the EMINAC scale (Fuentelsaz Gallego, 2001); 9) physical safety: active smoker, alcohol abuse and therapeutic devices (drainage and catheter); 10) communication: visual impairment (regular use of glasses or reduction in visual acuity), hearing impairment (use of a hearing aid, or deafness), language barriers, prior dementia or cognitive impairment (in a medical report or reported by the caregiver); 11) relations/esteem: history of social risk (social problem or social isolation) and family or caregiver support.

Other clinical variables included in the study were: age, sex, medical speciality, in-patient unit (medical or surgical), comorbidities (suffering from three or more simultaneous chronic diseases, or diseases coexisting with the principal diagnosis) and polypharmacy (active use 
of three or more drugs) or use of certain types of drug (anticholinergics, benzodiazepines, antidepressants, antipsychotics, or anticonvulsants). All the variables studied were dichotomous, except for age, which was considered as a continuous quantitative variable. Data from patients' clinical records were reviewed retrospectively.

\section{Statistical analysis}

The Pearson chi-square test was used to compare proportional differences between the two groups of patients for dichotomous variables, and Student's independent samples t-test was used to examine differences in mean ages and the number of risk factors between the groups. A univariate logistic regression was performed to identify significantly or nearly significantly associated variables $(p<0.1)$, all of which were included in a multivariate analysis to determine the independently significant variables $(p<0.05)$ predictive of delirium. To generate the multivariate analysis we applied the "mice" package implemented in R, which applies Gibbs sampling, which is a method for imputing missing data. This step allows us to replace missing data with values estimated on the basis of the other information available for the other patients.

We subsequently used the Lasso technique to ensure that variables were not overfitted, by eliminating variables from the model if that action did not alter the model's predictive power. This step gives a model that will fit better when it is generalized to other cases. In effect, the lasso technique sets to zero the coefficients of variables that are not helpful for making correct predictions from the new data.

After applying the lasso technique, we carried out a 10-fold cross-validation to assess the validity of the model generated. We selected $90 \%$ of the patients and divided them into 10 packages with equal numbers in each. We then generated a multivariate logistic regression model using nine of the packages of patients. We repeated this step a further nine times, using different combinations of the 10 packages, and selected the best model of the 10 generated. We then tested it on the data of the remaining original $10 \%$ of patients. Sensitivity, specificity and the ROC curve were also calculated for the multivariate logistic regression model.

This article is protected by copyright. All rights reserved. 


\section{Ethical aspects}

The study was evaluated and approved by the research ethics committee of the Hospital Joan XXIII (CI reference 34/2014). The type of study and the method of data collection ensured an equitable balance between costs and benefits of participation. Anonymity and confidentiality (access to records, data encryption and archiving of information) were guaranteed throughout the entire research process.

\section{Results}

We studied 454 patients (150 with and 304 without delirium). Of those with delirium, 73 (48.67\%) were male; $151(49.7 \%)$ of control patients (without delirium) were male, paired according to sex.

The anticipated distribution was observed for the selection of patients paired by speciality and in-patient unit (Table 2). Of the 150 patients with delirium, $96(64.0 \%)$ were from surgical units and $54(36.0 \%)$ were from medical units. Of the 304 patients without delirium, 198 $(65.1 \%)$ had been admitted to surgical units and 106 (34.9\%) came from medical units. Thus, pairing the patients and controls by sex, medical specialty and in-patient unit ensured approximately equal proportions of each of the three factors. The chi-squared test identified no statistically significant differences between cases and controls, demonstrating that the cases and controls were correctly matched. Matching with respect to these variables was important to avoid ascertainment bias, especially for the medical speciality and in-patient unit, because the risk of having delirium is higher than in some of the specialities and units than others.

Statistically significant differences in mean age were found between the samples of patients with and without delirium. The mean ages of patients with and without delirium were 84.64 $(\mathrm{SD}, 6.92)$ and $78.04(\mathrm{SD}, 6.82)$ years, respectively.

Considering the variables listed in the nursing assessment form, significantly more risk factors were identified among the patients who presented delirium than among those who did not (13.0 vs. $7.4 ; \mathrm{p}<0.001)$. 
All of the variables from the nursing assessment and other factors that were examined with chi-square tests differed significantly between the two groups (Table 3), except for: fever on admission, visual impairment and caregiver support. The presence of devices for improving physical safety was a significant protective factor.

The variables analysed in the univariate and multivariate predictive models are shown in Table 4. Most of the factors from the nursing assessment were significant in the univariate model. The significant care needs and areas including the factors identified were: breathing, nutrition, elimination, mobility, rest and sleep, self-care, physical safety, communication, relationships and esteem.

After including the significant risk factors and those with values of $p<0.1$ in the initial multivariate model, eight factors proved to be independently predictive in the final model: age, urinary incontinence, urinary catheter, alcohol abuse, previous history of dementia, being able to get out of bed/not being at rest, habitual insomnia and history of social risk. The results of the multivariate analysis are presented in Table 4. These reveal that there was a $15 \%$ risk of having delirium per extra year of age. With respect to the categorical variables, the highest ORs were found in the patients with habitual insomnia or who consumed excessive amounts of alcohol. Patients in both groups had around 16 times the risk of developing delirium than patients without these problems. Patients with a history of social risk also had 7.35 times the risk of developing delirium than those without such a history. The other four risk factors had ORs between 2.5 and 4.2.

The residuals of the final model were very small, as indicated by the very significant goodness of fit $(p<0.001)$ revealed by the Hosmer-Lemeshow test.

The predictive ability of the multivariate model in the training set of $90 \%$ of the patients was assessed by calculating the ROC curve, which compares the predicted and observed percentages of patients with delirium. The value of the area under the ROC curve in the proposed multivariate model was 0.945 (95\% confidence interval $(\mathrm{Cl}): 0.922-0.970)$. The model was applied to the test set, comprising the remaining $10 \%$ of the original sample of patients, and was found to be able to correctly classify $93.3 \%$ of the patients.

This article is protected by copyright. All rights reserved. 
The new model's sensitivity for predicting cases (patients with delirium) was $94.6 \%$ and its specificity for predicting the absence of delirium was $89.4 \%$.

\section{Discussion}

This study uses the manifestations of dependency on care to evaluate the comprehensive nursing assessment as a tool for determining the risk of delirium in older hospitalised patients. According to the classification of (Grover \& Kate, 2012) it could be considered an effective tool for assessing risk factors since it identifies the specific areas of care required by the person assessed.

\section{Recording the episode of delirium in the clinical history}

Some studies have drawn attention to the poor recording of episodes of delirium in patients' clinical documentation (Alagiakrishnan et al., 2009; El Hussein, Hirst, \& Salyers, 2015; Voyer, McCusker, Cole, St-Jacques, \& Khomenko, 2007). The results of our study highlight the importance of nursing assessment in delirium prevention, so the next step would be to insist on the importance of registering and correctly completing the nursing assessment form.

The advantage of the comprehensive nursing assessment is that it is not a separate record but, rather, part of the electronic clinical records of all the hospitals in our organisation (JuveUdina, 2013). Being able to use it to identify the risk of delirium will enable improved recording of this information. Having all this information in the patient's history and not in other separate records (scales or specific forms) offers a better approach for preventing delirium. Information about all the variables included in the nursing assessment is usually collected as soon as the patient is admitted to the nursing unit, and must be completed within $24 \mathrm{~h}$.

This article is protected by copyright. All rights reserved. 


\section{The multifactorial origin of delirium and comprehensive nursing assessment}

As in the other studies reviewed here, this new, nursing perspective-based risk assessment model could be used to confirm delirium as a set of symptoms of multifactorial origin (S. K. Inouye et al., 2014; Newman et al., 2015; Whittamore et al., 2014).

We should also bear in mind the difficulty of comparing the results of different studies that arises from the heterogeneity arising from measuring single risk factors, such as polypharmacy, comorbidity, dementia, dependency for self-care, among others (Newman et al., 2015; Perello Campaner, 2010).

Various factors and care needs were identified in our study as being risk factors in the comprehensive nursing assessment. Disturbances in respiration, nutrition, elimination, mobility, rest and sleep, self-care, physical safety, communication and relationships and esteem proved to be the needs that are associated with manifestations of dependency identified as being a risk for delirium.

Advanced age is one of the most widely accepted risk factors for delirium identified in this study. Although we only considered people aged 65 years or more, we found statistically significant differences in age between the two groups. The studies show that vulnerability increases with age, but when a minimum age for participation is a selection criterion (as in our case) the associative strength of this variable in relation to delirium may be less (Newman et al., 2015; Pendlebury et al., 2016). As in other studies, age was also an independent predictor of delírium in our multivariate model. Based on the results of the predictive model, we can conclude that as age increases, more risk factors appear and vulnerability to delirium increases.

Prior dementia or cognitive impairment consistently appears as a predictive factor in most, but, surprisingly, given its well established importance, not in all the proposed risk models (Ahmed et al., 2014; Newman et al., 2015; Perello Campaner, 2010). This risk factor was one of the eight predictive factors identified in our study.

Significant differences were also found in comorbidity and polypharmacy in the univariate analyses, but they did not prove to be independent predictive factors for delirium in the 
multivariate model. High comorbidity and severe illness have been identified as predictors of delirium in some predictive models (Douglas et al., 2013; S. K. Inouye et al., 2007; Rudolph et al., 2011).

There were significant differences in the medium or high level of dependence for ADL between the two groups. Note that dependency for ADL (Martinez et al., 2012), ADL impairment (S. K. Inouye et al., 2007; Kobayashi, Takahashi, Arioka, Koga, \& Fukui, 2013) and the Barthel Index (ADLs) (Carrasco, Villarroel, Andrade, Calderon, \& Gonzalez, 2014), were independent predictors in validated risk-stratification models.

The seven independent predictive categorical factors (in addition to age) identified from the comprehensive nursing assessment were: urinary incontinence and use of a urinary catheter (need for elimination), not getting out of bed (need for mobility), difficulty sleeping (need for rest and sleep), prior dementia or cognitive impairment (need for communication), alcohol abuse (need for safety) and history of social risk (need for relations).

Compared with other predictive models that propose risk assessment scales for delirium (Ahmed et al., 2014; Newman et al., 2015; Perello Campaner, 2010), our model has good predictive capability and accuracy (as indicated by the high value of the ROC curve) for these eight independent factors taken from the comprehensive nursing assessment. The high predictive power of the model was partially due to the use of the Gibbs and Lasso techniques. The cross-validation used in the study enabled the model variables to be validated.

\section{Comprehensive nursing assessment and multicomponent programmes}

The areas of care and the risk factors identified using the comprehensive nursing assessment instrument broadly coincide with those of the protocols and basic interventions in the multicomponent HELP program (Chen et al., 2015; Hshieh et al., 2015; Yue et al., 2014).

This article is protected by copyright. All rights reserved. 
Risk factors identified as predictors of delirium from the comprehensive nursing assessment indicate specific areas of care for the prevention of delirium. These areas broadly match the interventions defined in the ten protocols of the HELP program.

The comprehensive nursing assessment can be considered an effective instrument for identifying risks of delirium and for the subsequent implementation of a personalised care plan based on specific interventions for individual patients.

\section{Conclusions}

Comprehensive nursing assessment may be an effective strategy and a useful alternative for focusing interventions on patients at risk in hospitals where no multicomponent strategies or programmes for the prevention and management of delirium have so far been implemented. Our findings suggest that being able to identify the risks at the time of patient admission may help the care team focus on the most vulnerable individuals and plan an effective care strategy aimed at preventing and managing delirium. Nevertheless, there is a need to make nursing professionals more aware of the importance of a correct nursing assessment of risk from delirium to facilitate accurate care planning.

\section{Relevance to clinical practice}

The comprehensive nursing assessment (the first part of the nursing care process) is an instrument that is extensively included and broadly recognised in nursing practice, so its acceptance and application as a risk assessment of delirium is feasible. The widespread use of the nursing assessment as an effective tool for delirium risk evaluation could allow the use of preventive actions as soon as the patient is first hospitalized. Delirium risk evaluation using the nursing assessment may be readily accepted by nurses and can be effective for the subsequent planning of the necessary individualized aspects of care identified from a model of care based on needs. Several studies indicate that, from the point of view of prevention, it is particularly important to identify patients who might benefit from

This article is protected by copyright. All rights reserved. 
multicomponent interventions. Nevertheless, scales of risk assessment from validated predictive models that identify patients who are at high risk of developing delirium are not well known or not widely used by health professionals, so the recognition of delirium and its risks by doctors and nurses remains limited. Consequently, delirium is usually addressed in a complex, deficient and delayed manner.

The results show a considerable number of variables to be associated to delirium and all of them are included in the nursing assessment. The multivariate model has been validated in patients from the same hospital, but to extend the use of the nursing assessment for delirium risk evaluation, the model presented here should be validated in other hospitals to establish its external validity. Nevertheless, the model shows that by using only 8 of 27 variables included in the nursing assessment it is possible to correctly classify more than $90 \%$ of the hospitalized patients who could be at risk of delirium. These findings indicate that nursing assessment could be a powerful tool in the daily practice of nurses for preventing delirium.

\section{References}

Adamis, D., Sharma, N., Whelan, P.J., Macdonald, A.J., 2010. Delirium scales: A review of current evidence. Aging Ment Health 14 (5), 543-555. http://dx.doi.org/10.1080/13607860903421011

Ahmed, S., Leurent, B., Sampson, E.L., 2014. Risk factors for incident delirium among older people in acute hospital medical units: a systematic review and meta-analysis. Age Ageing 43 (3), 326-333. http://dx.doi.org/10.1093/ageing/afu022

Alagiakrishnan, K., Marrie, T., Rolfson, D., Coke, W., Camicioli, R., Duggan, D., Launhardt, B., Fisher, B., Gordon, D., Hervas-Malo, M., Magee, B., Wiens, C., 2009. Gaps in patient care practices to prevent hospital-acquired delirium. Can Fam Physician 55 (10), e41-46. http://www.ncbi.nlm.nih.gov/pubmed/19826141

APA, 2013. Diagnostic and Statistical Manual of Mental Disorders DSM-V. Fifth Edition. Washington, DC: American Psychiatric Association., Washington, DC: American Psychiatric Association.

This article is protected by copyright. All rights reserved. 
Avendano-Cespedes, A., Garcia-Cantos, N., Gonzalez-Teruel Mdel, M., Martinez-Garcia, M., Villarreal-Bocanegra, E., Oliver-Carbonell, J.L., Abizanda, P., 2016. Pilot study of a preventive multicomponent nurse intervention to reduce the incidence and severity of delirium in hospitalized older adults: MID-Nurse-P. Maturitas 86, 86-94. http://dx.doi.org/10.1016/j.maturitas.2016.02.002

Cole, M.G., Ciampi, A., Belzile, E., Dubuc-Sarrasin, M., 2013. Subsyndromal delirium in older people: a systematic review of frequency, risk factors, course and outcomes. Int J Geriatr Psychiatry 28 (8), http://dx.doi.org/10.1002/gps.389

Chen, P., Dowal, S., Schmitt, E., Habtemariam, D., Hshieh, T.T., Victor, R., Boockvar, K.S., Inouye, S.K., 2015. Hospital Elder Life Program in the real world: the many uses of the Hospital Elder Life Program website. J Am Geriatr Soc 63 (4), 797-803. http://dx.doi.org/10.1111/jgs.13343

Day, J., Higgins, I., Koch, T., 2009. The process of practice redesign in delirium care for hospitalised older people: a participatory action research study. Int J Nurs Stud 46 (1), 13-22. http://dx.doi.org/10.1016/j.ijnurstu.2008.08.013

de Castro, S.M., Unlu, C., Tuynman, J.B., Honig, A., van Wagensveld, B.A., Steller, E.P., Vrouenraets, B.C., 2014. Incidence and risk factors of delirium in the elderly general surgical patient. Am J Surg 208 (1), 26-32. http://dx.doi.org/10.1016/j.amjsurg.2013.12.02

El Hussein, M., Hirst, S., Salyers, V., 2015. Factors that contribute to underrecognition of delirium by registered nurses in acute care settings: a scoping review of the literature to explain this phenomenon. J Clin Nurs 24 (7-8), 906-915. http://dx.doi.org/10.1111/jocn.12693

Gonzalez, M., de Pablo, J., Fuente, E., Valdes, M., Peri, J.M., Nomdedeu, M., Matrai, S., 2004. Instrument for detection of delirium in general hospitals: adaptation of the confusion assessment method. Psychosomatics 45 (5), 426-431. http://dx.doi.org/10.1176/appi.psy.45.5.426

This article is protected by copyright. All rights reserved. 
Grover, S., Kate, N., 2012. Assessment scales for delirium: A review. World J Psychiatry 2 (4), 58-70. http://dx.doi.org/10.5498/wjp.v2.i4.58

Hasemann, W., Tolson, D., Godwin, J., Spirig, R., Frei, I.A., Kressig, R.W., 2016. A before and after study of a nurse led comprehensive delirium management programme (DemDel) for older acute care inpatients with cognitive impairment. Int J Nurs Stud 53, 27-38. http://dx.doi.org/10.1016/j.jjnurstu.2015.08.003

Henao-Castano, A.M., Amaya-Rey, M.C., 2014. Nursing and patients with delirium: a literature review. Invest Educ Enferm 32 (1), 148-156.

http://www.ncbi.nlm.nih.gov/pubmed/25229914 http://dx.doi.org/10.1590/S0120-53072014000100017

Henderson, V., 1994. La naturaleza de la enfermería: una definición y sus repercusiones en la práctica, la investigación y la educación, reflexiones 25 años después., Mexico: McGraw-Hill Interamericana.

Hshieh, T.T., Yue, J., Oh, E., Puelle, M., Dowal, S., Travison, T., Inouye, S.K., 2015. Effectiveness of multicomponent nonpharmacological delirium interventions: a metaanalysis. JAMA Intern Med 175 (4), 512-520. http://dx.doi.org/10.1001/jamainternmed.2014.7779

Hsieh, S.J., Madahar, P., Hope, A.A., Zapata, J., Gong, M.N., 2015. Clinical deterioration in older adults with delirium during early hospitalisation: a prospective cohort study. BMJ Open 5 (9), e007496. http://dx.doi.org/10.1136/bmjopen-2014-007496 Inouye, S., van Dyck, C., Alessi, C., Balkin, S., Siegal, A., Horwitz, R., 1990. Clarifying confusion: the Confusion Assessment Method: a new method for detection of delirium. Ann Intern Med 113, 941-948.

http://www.ncbi.nlm.nih.gov/pubmed/2240918

Inouye, S.K., Westendorp, R.G., Saczynski, J.S., 2014. Delirium in elderly people. Lancet 383 (9920), 911-922. http://dx.doi.org/10.1016/S0140-6736(13)60688-1

This article is protected by copyright. All rights reserved. 
Juve-Udina, M.E., 2013. What patients' problems do nurses e-chart? Longitudinal study to evaluate the usability of an interface terminology. Int J Nurs Stud 50 (12), 1698-1710. http://dx.doi.org/10.1016/j.jinurstu.2013.04.008

Kozier, B., Erb, G., Blais, K., \& Wilkinson, J.M., 2005. Fundamentals of nursing concepts and procedures., Mexico DF: McGraw-Hill Interamericana.

Martins, S., Fernandes, L., 2012. Delirium in elderly people: a review. Front Neurol 3, 101. http://dx.doi.org/10.3389/fneur.2012.00101

McCleary, E., Cumming, P., 2015. Improving early recognition of delirium using SQiD (Single Question to identify Delirium): a hospital based quality improvement project. BMJ Qual Improv Rep 4 (1). http://dx.doi.org/10.1136/bmjquality.u206598.w2653

Newman, M.W., O'Dwyer, L.C., Rosenthal, L., 2015. Predicting delirium: a review of riskstratification models. Gen Hosp Psychiatry 37 (5), 408-413. http://dx.doi.org/10.1016/j.genhosppsych.2015.05.003

Pendlebury, S.T., Lovett, N., Smith, S.C., Cornish, E., Mehta, Z., Rothwell, P.M., 2016. Delirium risk stratification in consecutive unselected admissions to acute medicine: validation of externally derived risk scores. Age Ageing 45 (1), 60-65. http://dx.doi.org/10.1093/ageing/afv177

Perello Campaner, C., 2010. [Delirium risk assessment in elderly hospitalized patients]. Rev Esp Geriatr Gerontol 45 (5), 285-290. http://dx.doi.org/10.1016/j.regg.2010.03.011

Rudolph, J.L., Harrington, M.B., Lucatorto, M.A., Chester, J.G., Francis, J., Shay, K.J., 2011. Validation of a medical record-based delirium risk assessment. J Am Geriatr Soc 59 Suppl 2, S289-294. http://dx.doi.org/10.1016/j.jamda.2015.10.020

Strijbos, M.J., Steunenberg, B., van der Mast, R.C., Inouye, S.K., Schuurmans, M.J., 2013. Design and methods of the Hospital Elder Life Program (HELP), a multicomponent targeted intervention to prevent delirium in hospitalized older patients: efficacy and cost-effectiveness in Dutch health care. BMC Geriatr 13, 78. http://dx.doi.org/10.1186/1471-2318-13-78

This article is protected by copyright. All rights reserved. 
Suhonen, R., Gustafsson, M.L., Katajisto, J., Valimaki, M., Leino-Kilpi, H., 2010. Nurses' perceptions of individualized care. J Adv Nurs 66 (5), 1035-1046. http://dx.doi.org/10.1111/j.1365-2648.2009.05256.x

Suhonen, R., Valimaki, M., Leino-Kilpi, H., 2008. A review of outcomes of individualised nursing interventions on adult patients. J Clin Nurs 17 (7), 843-860. http://dx.doi.org/10.1111/j.1365-2702.2007.01979.x

Vidan, M.T., Sanchez, E., Alonso, M., Montero, B., Ortiz, J., Serra, J.A., 2009. An intervention integrated into daily clinical practice reduces the incidence of delirium during hospitalization in elderly patients. J Am Geriatr Soc 57 (11), 2029-2036. http://dx.doi.org/10.1111/j.1532-5415.2009.02485.x

Voyer, P., McCusker, J., Cole, M.G., St-Jacques, S., Khomenko, L., 2007. Factors associated with delirium severity among older patients. J Clin Nurs 16 (5), 819-831. http://dx.doi.org/10.1111/j.1365-2702.2006.01808.x

Wei, L.A., Fearing, M.A., Sternberg, E.J., Inouye, S.K., 2008. The Confusion Assessment Method: a systematic review of current usage. J Am Geriatr Soc 56 (5), 823-830. http://dx.doi.org/10.1111/j.1532-5415.2008.01674.x

Whittamore, K.H., Goldberg, S.E., Gladman, J.R., Bradshaw, L.E., Jones, R.G., Harwood, R.H., 2014. The diagnosis, prevalence and outcome of delirium in a cohort of older people with mental health problems on general hospital wards. Int J Geriatr Psychiatry 29 (1), 32-40. http://dx.doi.org/10.1002/gps.3961

Yue, J., Tabloski, P., Dowal, S.L., Puelle, M.R., Nandan, R., Inouye, S.K., 2014. NICE to HELP: operationalizing National Institute for Health and Clinical Excellence guidelines to improve clinical practice. J Am Geriatr Soc 62 (4), 754-761. http://dx.doi.org/10.1111/jgs.12768

This article is protected by copyright. All rights reserved. 
Table 1. Relationship between the care needs of the model and the NICE Guideline on delirium, the HELP Protocols and the risk factors described in the literature.

\begin{tabular}{|c|c|c|c|}
\hline $\begin{array}{l}\text { Nursing assessment } \\
\text { Altered need }\end{array}$ & $\begin{array}{c}\text { NICE } \\
\text { Clinical Factor }\end{array}$ & $\begin{array}{c}\text { HELP } \\
\text { Protocols }\end{array}$ & $\begin{array}{l}\text { Predictive Models } \\
\text { Risk factors }\end{array}$ \\
\hline - Breathing & - Hypoxia & - Hypoxia Protocol & \\
\hline \multirow[t]{2}{*}{ - Nutrition } & $\begin{array}{l}\text { - Dehydration or } \\
\text { Constipation }\end{array}$ & $\begin{array}{l}\text { - Expansion of Fluid } \\
\text { Repletion Protocol }\end{array}$ & - Dehydration \\
\hline & - Poor Nutrition & $\begin{array}{l}\text { - Feeding Assistance } \\
\text { Protocol }\end{array}$ & \\
\hline $\begin{array}{l}\text { - Urinary and faecal } \\
\text { elimination }\end{array}$ & & & $\begin{array}{l}\text { - ADL impairment/ } \\
\text { functional impairment }\end{array}$ \\
\hline - Mobilisation & $\begin{array}{l}\text { - Immobility or Limited } \\
\text { Mobility }\end{array}$ & $\begin{array}{l}\text { - Early Mobilization } \\
\text { Protocol }\end{array}$ & \\
\hline \multirow[t]{2}{*}{$\begin{array}{l}\text { - Rest and sleep/Well- } \\
\text { being }\end{array}$} & - Pain & $\begin{array}{l}\text { - Pain Management } \\
\text { Protocol }\end{array}$ & \\
\hline & - Sleep Disturbance & $\begin{array}{l}\text { - Sleep Enhancement } \\
\text { Protocol }\end{array}$ & \\
\hline $\begin{array}{l}\text { - Self-care /dressing, } \\
\text { undressing }\end{array}$ & & & $\begin{array}{l}\text { - ADL impairment/ } \\
\text { functional impairment }\end{array}$ \\
\hline - Body temperature & - Infection & $\begin{array}{l}\text { - Infection Prevention } \\
\text { Protocols }\end{array}$ & \\
\hline $\begin{array}{l}\text { - Hygiene/Skin } \\
\text { protection }\end{array}$ & & & $\begin{array}{l}\text { - ADL impairment/ } \\
\text { functional impairment }\end{array}$ \\
\hline \multirow[t]{2}{*}{$\begin{array}{l}\text { - Physical } \\
\text { safety/Avoidance of } \\
\text { hazards }\end{array}$} & - Infection & $\begin{array}{l}\text { - Therapeutic activities } \\
\text { Protocols }\end{array}$ & - latrogenic event \\
\hline & & & - Alcoholism \\
\hline $\begin{array}{l}\text { - Communication/ } \\
\text { Relations and Esteem }\end{array}$ & $\begin{array}{l}\text { - Cognitive impairment } \\
\text { or disorientation } \\
\text { - Sensory Impairment }\end{array}$ & $\begin{array}{l}\text { - Orientation/Therapeuti } \\
\text { c activities protocols } \\
\text { - Vision protocol / } \\
\text { Hearing Protocol }\end{array}$ & $\begin{array}{l}\text { - Disoriented/ cognitive } \\
\text { impairment } \\
\text { - Demencia } \\
\text { - Sensory Impairment }\end{array}$ \\
\hline
\end{tabular}

This article is protected by copyright. All rights reserved. 
Table 2: Distribution of patients studied according to the medical speciality to which they came from, and the in-patient unit (medical or surgical) according to the anticipated ratio of 1:2 when calculating the sample size of 1 case (patients with delirium) per 2 controls (patients without delirium) and paired data.

\begin{tabular}{lrrr}
\hline $\begin{array}{l}\text { Distribution ratio 1:2 } \\
\text { In-patient unit }\end{array}$ & $\begin{array}{c}\text { Patients } \\
\text { with delirium }\end{array}$ & $\begin{array}{c}\text { Patients } \\
\text { without delirium }\end{array}$ & All patients \\
\hline Surgical speciality & $68(44,0 \%)$ & $140(46,0 \%)$ & $208(45,8 \%)$ \\
$\begin{array}{l}\text { Traumatology and orthopaedic } \\
\text { surgery }\end{array}$ & $22(14,7 \%)$ & $46(15,1 \%)$ & $68(15,0 \%)$ \\
$\begin{array}{l}\text { General surgery } \\
\text { Urology }\end{array}$ & $6(4,0 \%)$ & $12(3,9 \%)$ & $18(4,0 \%)$ \\
$\begin{array}{l}\text { All surgical patients } \\
\text { ratio 1:2 }\end{array}$ & $96(62,7 \%)$ & $198(65,0 \%)$ & $294(64,8 \%)$ \\
\hline $\begin{array}{l}\text { Medical speciality } \\
\text { Internal medicine }\end{array}$ & $40(26,7 \%)$ & $78(25,7 \%)$ & $118(26,0 \%)$ \\
$\begin{array}{l}\text { Neurology } \\
\text { Other medical specialities }\end{array}$ & $9(6 \%)$ & $17(5,6 \%)$ & $26(5,7 \%)$ \\
$\begin{array}{l}\text { All medical patients } \\
\%\end{array}$ & $5(3,3 \%)$ & $11(3,6 \%)$ & $16(3,5 \%)$ \\
\hline $\begin{array}{l}\text { All pationts 1:2 } \\
\text { ratio 1:2 }\end{array}$ & $54(33,8 \%)$ & $106(34,9 \%)$ & $160(35,2 \%)$ \\
\hline
\end{tabular}

This article is protected by copyright. All rights reserved. 
Table 3: Results in the Student's T-test for the variable age (mean and standard deviation) and of the Pearson chi-square test between the sample of patients with delirium (cases) and patients without delirium (controls) for dichotomous variables (admission data).

\begin{tabular}{|c|c|c|c|}
\hline VARIBLES & $\begin{array}{l}\text { Patients delirium } \\
\text { cases }=150\end{array}$ & $\begin{array}{c}\text { Patients without } \\
\text { delirium } \\
\text { controls }=304\end{array}$ & $\mathbf{p}$ \\
\hline Age & $84,64(6.82)$ & $78.04(6.92)$ & $<0.001$ \\
\hline Comorbidities & $131(88.5 \%)$ & $226(80.7 \%)$ & 0.041 \\
\hline Polypharmacy / use of other drugs & $115(77.7 \%)$ & $182(64.5 \%)$ & 0.006 \\
\hline \multicolumn{4}{|l|}{ Altered need } \\
\hline \multicolumn{4}{|l|}{ Breathing } \\
\hline Breathlessness/dyspnoea & $54(36.5 \%)$ & $75(25.8 \%)$ & 0.026 \\
\hline Respiratory infection & $33(22.6 \%)$ & $51(17.6 \%)$ & 0.247 \\
\hline Oxygen therapy & 57 (39.0\%) & $72(25.3 \%)$ & 0.004 \\
\hline \multicolumn{4}{|l|}{ Nutrition/feeding } \\
\hline Fluid therapy & $79(56.0 \%)$ & $75(26.3 \%)$ & $<0.001$ \\
\hline Signs of dehydration & $31(20.9 \%)$ & $33(11.2 \%)$ & 0.009 \\
\hline Restrictive diet & $53(35.33 \%)$ & $56(18.42 \%)$ & $<0.001$ \\
\hline \multicolumn{4}{|l|}{ Elimination/toilet } \\
\hline Urinary incontinence & $103(69.1 \%)$ & $43(14.5 \%)$ & $<0.001$ \\
\hline Faecal incontinence & $63(43.3 \%)$ & $13(4.4 \%)$ & $<0.001$ \\
\hline Urinary retention & $22(15.3 \%)$ & $8(2.7 \%)$ & $<0.001$ \\
\hline Dysuria infection & $11(7.6 \%)$ & $4(1.3 \%)$ & $<0.001$ \\
\hline Uses urinary catheter & $58(39.2 \%)$ & $60(20.3 \%)$ & $<0.001$ \\
\hline Constipation or diarrhoea & $43(29.1 \%)$ & $27(9.2 \%)$ & $<0.001$ \\
\hline \multicolumn{4}{|l|}{ Mobilisation } \\
\hline Rest in bed & $112(74.6 \%)$ & $185(59.4 \%)$ & 0.002 \\
\hline \multicolumn{4}{|l|}{ Rest and sleep/Well-being } \\
\hline Habitual insomnia & $132(89 \%)$ & $68(24.1 \%)$ & $<0.001$ \\
\hline \multicolumn{4}{|l|}{ Hygiene and integument } \\
\hline Ulcer risk due to moderate or high pressure & $109(72.7 \%)$ & $43(33.1 \%)$ & $<0.001$ \\
\hline \multicolumn{4}{|l|}{ Self-care/level of dependence } \\
\hline Medium/high dependency or & $133(91.1 \%)$ & $202(68.2 \%)$ & $<0.001$ \\
\hline Total inability for self-care & $109(73.6 \%)$ & $74(25.2 \%)$ & $<0.001$ \\
\hline \multicolumn{4}{|l|}{ Body temperature } \\
\hline Fever on admission & $42(36.5 \%)$ & $127(42.5 \%)$ & 0.315 \\
\hline \multicolumn{4}{|l|}{ Physical safety/Avoidance of hazards } \\
\hline Active smoker & $12(8.5 \%)$ & $10(3.4 \%)$ & 0.034 \\
\hline Alcohol abuse & $13(9.1 \%)$ & $5(1.7 \%)$ & 0.001 \\
\hline Therapeutic devices & $14(18.4 \%)$ & $40(31.5 \%)$ & 0.049 \\
\hline \multicolumn{4}{|l|}{ Communication } \\
\hline Visual deficit & $51(38.9 \%)$ & $119(45.4 \%)$ & 0.236 \\
\hline Hearing loss & $43(31.4 \%)$ & $51(18.0 \%)$ & 0.003 \\
\hline Language barriers & $10(6.8 \%)$ & $2(0.7 \%)$ & $<0.001$ \\
\hline Dementia or cognitive impairment & $92(62.6 \%)$ & $73(25.7 \%)$ & $<0.001$ \\
\hline \multicolumn{4}{|l|}{ Relations/Esteem } \\
\hline History of social risk & $31(22.0 \%)$ & $9(3.0 \%)$ & $<0.001$ \\
\hline Family support & 115 (77.7\%) & $226(76.9 \%)$ & 0.905 \\
\hline
\end{tabular}

This article is protected by copyright. All rights reserved. 
Table 4. Univariate and multivariate predictive logistic regression model for delirium risk prediction.

\begin{tabular}{|c|c|c|c|c|c|c|}
\hline \multirow[b]{2}{*}{ VARIABLES } & \multicolumn{3}{|c|}{$\begin{array}{c}\text { Univarible } \\
\text { Model }\end{array}$} & \multicolumn{3}{|c|}{$\begin{array}{c}\text { Multivariable } \\
\text { Model }\end{array}$} \\
\hline & OR & IC 95\% & $p$ & OR & IC 95\% & $p$ \\
\hline Age & 1.15 & $1.11-1.19$ & $<0.001$ & 1.15 & $1.09-1.21$ & $<0.001$ \\
\hline Comorbidities & 1.88 & $1.05-3.36$ & 0.035 & & & \\
\hline Polypharmacy /other drugs & 1.94 & $1.23-3.06$ & 0.004 & & & \\
\hline \multicolumn{7}{|l|}{ Breathing } \\
\hline Breathlessness/dyspnoea & 1.70 & $1.11-2.60$ & 0.014 & & & \\
\hline Oxygen therapy & 1.91 & $1.25-2.93$ & 0.003 & & & \\
\hline \multicolumn{7}{|l|}{ Nutrition } \\
\hline Treatment with serum therapy & 3.54 & $3.54-5.40$ & $<0.001$ & & & \\
\hline Signs of dehydration & 2.10 & $1.23-3.58$ & 0.007 & & & \\
\hline Restrictive diet & 1.53 & $1.70-1.80$ & $<0.001$ & & & \\
\hline \multicolumn{7}{|l|}{ Elimination } \\
\hline Urinary incontinence & 13.49 & $8.39-21.67$ & $<0.001$ & 4.25 & $2.14-8.64$ & $<0.001$ \\
\hline Faecal incontinence & 17.08 & $8.96-32.57$ & $<0.001$ & & & \\
\hline Urinary retention & 6.65 & $2.88-15.35$ & $<0.001$ & & & \\
\hline Dysuria infection & 6.18 & $1.93-19.77$ & $<0.001$ & & & \\
\hline Uses urinary catheter & 2.60 & $1.68-4.01$ & $<0.001$ & 3.90 & $1.85-8.62$ & 0.001 \\
\hline Constipation or diarrhoea & 4.11 & $2.42-6.99$ & $<0.001$ & & & \\
\hline \multicolumn{7}{|l|}{ Mobilisation } \\
\hline Rest in bed, unable to get up & 1.50 & $1.32-1.78$ & 0.002 & 2.51 & $1.19-5.43$ & 0.023 \\
\hline \multicolumn{7}{|l|}{ Rest and sleep/Well-being } \\
\hline Habitual insomnia & 26.19 & $14.59-47.01$ & $<0.001$ & 16.58 & $7.87-37.90$ & $<0.001$ \\
\hline \multicolumn{7}{|l|}{ Self-care } \\
\hline Medium/high dependency & 4.62 & $2.49-8.59$ & $<0.001$ & & & \\
\hline Total inability for self-care & 8.54 & $5.44-13.39$ & $<0.001$ & & & \\
\hline \multicolumn{7}{|l|}{ Physical safety } \\
\hline Active smoker & 2.43 & $1.04-5.65$ & 0.04 & & & \\
\hline Alcohol abuse & 5.92 & $2.07-16.95$ & 0.001 & 16.20 & $2.34-130.98$ & 0.011 \\
\hline Therapeutic devices & 0.49 & $0.25-0.99$ & 0.047 & & & \\
\hline \multicolumn{7}{|l|}{ Communication } \\
\hline Hearing loss & 2.09 & $1.30-3.33$ & 0.002 & & & \\
\hline Language barriers & 10.66 & $2.30-49.30$ & 0.002 & & & \\
\hline $\begin{array}{l}\text { Dementia/cognitive } \\
\text { impairment } \\
\text { Relations/Esteem }\end{array}$ & 4.71 & $3.08-7.20$ & $<0.001$ & 3.46 & $1.74-7.07$ & $<0.001$ \\
\hline History of social risk & 9.18 & $4.23-19.89$ & $<0.001$ & 7.35 & $2.46-24.37$ & $<0.001$ \\
\hline
\end{tabular}

This article is protected by copyright. All rights reserved. 